Article

\title{
Proposing a Theoretical Framework for the Criminal Investigation of Human Trafficking Crimes
}

\author{
Laura Pajón* and Dave Walsh**
}

\begin{abstract}
Human Trafficking (HT) is considered as one of the most complex crimes to investigate. However, to date, little research has been conducted concerning what occurs during criminal investigations of HT. The present study, through interviewing 21 highly experienced and senior professionals from law enforcement agencies and governmental bodies in the UK, conceptualizes HT investigations under a common framework that underpins a model for the investigation of these crimes. Data from these narratives reveals that a total number of 22 investigative actions are commonly taken throughout the investigative process, following an apparent sequential route. While participants disagreed as to when/how to initiate and conclude an investigation, absolute agreement existed when considering multi-agency collaboration, tactical advice and support, and intelligence sharing (as core elements in HT criminal investigations). Such data enables both academic and practitioner communities to better identify what are effective investigation actions when these crimes are investigated.
\end{abstract}

\section{Introduction}

Despite the long history of Human Trafficking (HT), ${ }^{1}$ it has only been in the last couple of decades that HT has been considered as a serious social problem (Sigmon, 2008). Many countries, following the directives of the Palermo Protocol have implemented laws and policies intended to prosecute offenders, assist and protect victims, and ultimately, prevent HT (Konrad et al., 2017). Nonetheless, official figures are quite disappointing. Whereas measuring the prevalence of HT is complicated due to the clandestine and complex nature of the crime (Farrell et al., 2010; van der Watt and van der Westhuizen, 2017), sources estimate that there are still more than 40 million victims of trafficking around the world (The Global Index, 2017). Meanwhile, official reports suggest that only $1 \%$ of potential victims are actually identified (Department of State, 2013). These reported gaps concerning the number of trafficked people, the number of victims identified, and the actual HT crimes prosecuted highlight the overall ineffective response to HT.

\footnotetext{
*School of Social Sciences and Law, University of Derby, Room FG307, One Friar Gate Square, Derby, DE1 1DZ, UK. E-mail: L.PajonMoreno@derby.ac.uk

**School of Law, De Montfort University, Hugh Aston Building, Room 6.75, Leicester, LE2 7BY, UK

${ }^{1}$ For the purpose of this article the term HT will be used as a synonyms of Modern Slavery.
} 
The research community has contributed increasingly in efforts to enhance our understanding of the crime (e.g. examining sociodemographic characteristics of both victims and offenders and forms of exploitation) and to provide an evidence-based research that both informs and influences public policy responses (Konrad et al., 2017). However, our understanding remains far from complete (Van der Watt and Van der Westhuizen, 2017). Yet, less is understood concerning the criminal investigation of HT (Friesendorf, 2009; Verhoeven and Van Gestel, 2011). Indeed, Russell (2017) observed, when reviewing the salient literature, that "traffickers" and "law enforcement" were the least empirically studied aspects of the HT phenomenon. The present study aims to reduce this gap in our understanding by conceptualizing the criminal investigation of HT cases under a common theoretical framework, and encompassing various investigative actions undertaken during a HT investigation.

\section{Criminal investigation: background}

Criminal investigation is an information-rich and knowledge-intensive practice (Luen and AlHawamdeh, 2001; Chen et al., 2003), whose success depends on turning information into evidence (Berg et al., 2008). Smith and Flanagan (2000), defined the criminal investigation as a five-stage process, which consist of the following stages:

1. Initial case scene assessment

2. Assessment of incoming information

3. Selection of appropriate lines of enquiry

4. Case development, and

5. Post-charge case.

The nature of the investigative process implies that investigators need to acquire, transmit, and apply knowledge in all five stages to successfully answer the questions of how, where, when, why, and by whom a crime was committed (Stelfox, 2009). As such, Gottschalk (2006) argued that investigation teams possess the value configuration of a value shop. That is, an organization that creates value by solving unique problems through the use of knowledge (see Gottschalk, 2006 for a fuller explanation of the value shop model). Similar to the investigative stages proposed by Smith and Flanagan (2000), the Value Shop Model (VSM) is characterized by five main activities (Dean et al., 2006; Gottschalk, 2006):

1. Problem definition (i.e. type of offence and selection of the investigation team)

2. Investigative approaches (i.e. generation of hypothesis[es] and consideration of a range of strategies suitable to prove the offence)

3. Solution choice (i.e. selection of the most suitable investigative strategy to be implemented)

4. Solution execution (i.e. implementation of the investigative strategy)

5. Evaluation (i.e. ongoing and summative assessment of the chosen investigative strategy)

The VSM has been previously used with criminal investigation research to examine aspects such as predictors of police performance (e.g. Gottschalk, 2007) or use of knowledge management (e.g. Gottschalk and Holgersson, 2006), among others. The present study, similarly to previous research on criminal investigation, will use the dimensions of the VSM as a theoretical foundation because of their suitability when reflecting the main stages of any criminal investigation (Smith and Flanagan, 2000).

\section{The criminal investigation of HT}

HT has been considered as one of the most complex crimes to combat and investigate due to the large number of perpetrators and victims involved; the dynamic adaptation of the offenders (Bruns, 2015); cultural barriers often present between officers and victims (Kingshott, 2015); victim's uncertainty in regard to their own victimization (Gallagher and Holmes, 2008); and the scarcity of resources and available data-including inter-organizational reluctance to share data (Konrad et al., 2017). 
Contrary to other forms of criminality, intricacies of HT deny investigators the possibility of conducting a linear investigation process, where outcomes of an investigation are, relatively, predictable (Van der Watt, 2014). In light of such complexity, a need emerges for an integrated and innovative response to effectively tackle trafficking crimes, based on research evidence to enable the identification of best practices (UNODC, 2014; Verhoeven and Van Gestel, 2011). However, to date, most of the research that exists is based on case studies and therefore, extrapolation of best practices may be challenging due to either the singularity or the diversity of the cases examined. Moreover, what the scarce number of studies have found is that there is still a reliance on traditional investigative practices when investigating HT crimes (e.g. Farrell and Pfreffer, 2014). Therefore, a need for a model that provides professionals with a more detailed and evidence-based route of actions to follow when investigating a potential case of HT emerges.

\section{Methodology}

We used the VSM (Gottschalk, 2006) as theoretical foundation to build up a more tailored HT investigative framework that streams from the knowledge of the most experienced professionals working in the field of HT investigations in the UK. Thus, providing a route of actions for investigators to take when investigating HT cases as well as a theoretical framework for academics to use when exploring best practices in HT investigations.

A qualitative research design was used to conduct the study. Data was gathered through interviewees from very senior professionals from law enforcement agencies and governmental bodies in the UK, who (through their current roles) possessed extremely significant expertise in HT criminal investigations. Data was analysed through thematic analysis due to the suitability of the method to identify, analyse, and report patterns (themes), as well as to organize and describe the data set in rich detail (Braun and Clarke, 2006).

\section{Sample}

Our sampling strategy was purposive. After obtaining ethics authorization from the researchers' home University, data was collected from 21 very senior professionals from police forces, law enforcement agencies, and governmental bodies in the UK. Participants were selected according to their senior roles and levels of involvement in the criminal investigation of HT. Whereas directors and staff members from law enforcement agencies (e.g. Gangmasters and Labour Abuse Authority (GLAA), National Crime Agency (NCA)) and police forces were included in the sample, police officers composed most of the total sample $(n=14)$. These police officers held different ranks within their individual police force (ranging from Detective Inspectors to Chief Constables). Regardless of their job role, each participant was of a sufficiently senior status in their organization to contribute to the present study, each possessing at least 10 years' experience either of criminal investigation and/or HT investigations.

\section{Procedure}

The first researcher conducted semi-structured interviews, encouraging the participants to give free narratives. Interviews were conducted faceto-face or over the phone (being audio-recorded for their later transcription). The duration of the interviews varied from 1 hour to 2.5 hours (on average, around 90 minutes). Though, broadly, the same questions were put to each of the participants, they slightly differed depending on their role and the organization for whom they worked. Regardless, they all covered the following topics:

1. Exploration of the stages within HT criminal investigations 
2. Exploration of roles, duties, and operational organization for whom the interviewees work

3. Investigative strategies, and

4. Challenges when investigating HT crimes.

\section{Data analysis}

The thematic analysis of the data was conducted in two differentiated parts. First, a theoretical thematic analysis was conducted to identify the main dimensions within the criminal investigation of HT crimes (Braun and Clarke, 2006) using the VSM as a theoretical foundation for the analysis. Next, an inductive thematic analysis was conducted to identify the investigative actions taken within the investigation of HT crimes. Fig. 1 schematizes the methodological steps taken to conduct the analysis. Finally, a theoretical framework gathering the different investigative actions taken within the investigation was developed.

Theoretical thematic analysis. When conducting the theoretical thematic analysis,

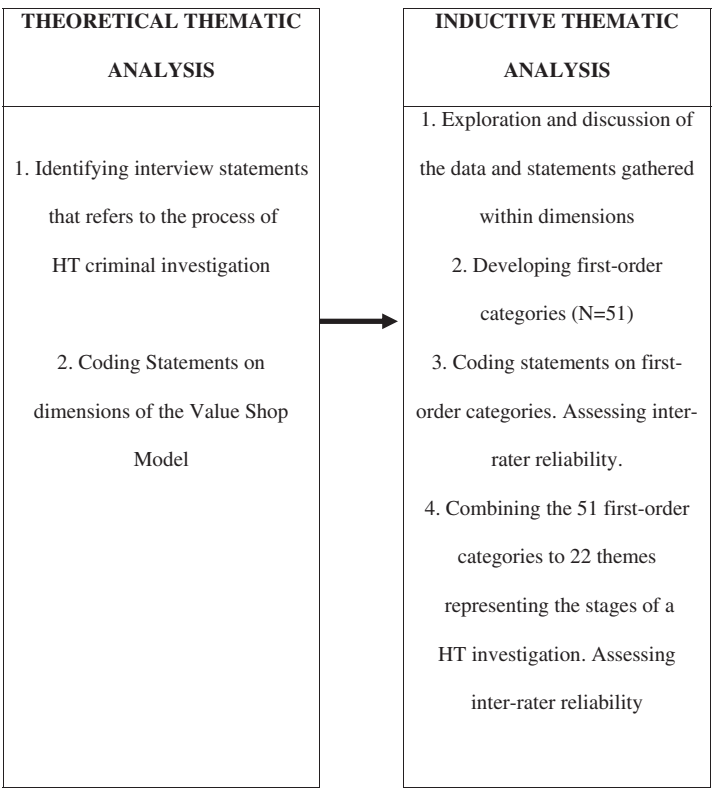

Figure 1: Summary of both conducted thematic analyses for the present study. statements from the data were identified by following the same definition used in previous qualitative studies (e.g. Lone et al., 2017) . This is:

A statement is a part of a sentence, a whole sentence, or several sentences expressed by the interviewee, that constitutes a coherent, meaningful point of view that describes an aspect of police investigative work.

We used the definition and description of the main dimensions of the VSM proposed by Gottschalk (2006) to identify the statements and grouped them within the main dimensions. See Appendix 1 for definitions and representative statements.

Inductive thematic analysis. Then, we conducted an inductive thematic analysis from the statements coded on the dimensions of the VSM. The analysis was conducted following the broad phases described by Braun and Clarke (2006). The first author fully familiarized herself with the data (i.e. conducting interviews, transcribing interviews, revising interviews, reading several times the full transcription of the interviews, coding statements within Value Shop dimensions, and revising several times statements within dimensions). From those steps firstorder categories were developed for each investigative phase by systematically identifying central features of the data. The first-order categories, and their nomenclature, were discussed and revised among the authors of the article, resulting in 51 first-order categories. Next, the statements were coded in the first-order categories, being possible to code a statement in more than one category. The inter-rater reliability on the coding of the 51 categories was assessed using the $23 \%$ of the sample ( $n=94$ statements). The independent inter-rater possessed both, academic background in criminal investigation (i.e. MSc in Criminal Investigation), and professional experience in policing. The inter-rater was trained by the first author to classify the statements in the proposed codes (it was possible that a statement could be classified in more than one category). Inter-reliability was 
assessed by using Cohen's Kappa. Results showed a good level of agreement ( $\mathrm{p}=0.77)$.

The researchers identified 22 themes, by combining the 51 first-order categories. The 22 themes represented the different actions taken within a HT criminal investigation (See Appendix 2). The reliability and validity of the themes for reflecting the investigative actions of HT investigations was tested by two independent coders selected by their extensive professional experience and knowledge of HT investigations in the UK (although they were not participants in the present study). They were debriefed about the purpose of the study and were given the description of each theme as well as the first-order categories gathered within the themes. By answering "yes" or "no", they were asked to indicate if our identified themes

1. Accurately represented the actions taken within a criminal investigation of HT

2. Encapsulated the first-order categories grouped within each theme; and

3. Reflected (in their nomenclature) both,

3.a. its description, and

3.b. the first-order categories gathered within each theme.

Inter-reliability was assessed for all three questions by using Cohen's Kappa between the first researcher and the first independent-coder; between the first researcher and the second independent-coder, and finally, between both independent-coders. Overall, results showed a strong level of agreement $(p=0.877)$. Because the name of the themes had the lowest rate of agreement $(\mathrm{p}=0.809)$ (see Table 1) a further discussion was conducted between the raters concerning the nomenclature of the themes to establish a suitable name for both the description of the theme, and also the representation of the first-order categories gathered within each theme. Seven modifications were made in total (see Appendix 3 for the final nomenclature, description, and firstorder categories gathered within each theme).

Investigative framework. After themes were identified and their reliability and validity tested, a theoretical framework was developed reflecting (i) the core actions taken within an investigation of HT and (ii) the interconnection of the investigative actions through the investigative process.

\section{Findings}

Our findings suggest that, similar to other crimes (e.g. homicide, sexual assaults), the investigation of HT crimes is also compatible with the dimensions proposed by the VSM: (i) problem definition; (ii) investigative approaches; (iii) solution choice; (iv) solution execution; and (v) evaluation. All transcriptions of the conducted interviews contained statements that could well be included in one of the five main dimensions of the VSM. All dimensions of the VSM were referred by the 21 participants, except for the evaluation stage that wasn't mentioned by one participant. On average, each dimension of the VSM gathered 67.4 statements $(\mathrm{SD}=18.9)$. Despite statements from the interviewees were able to be classified within the five main dimensions, the authors of the article observed that sub-categories could be identified within the broad VSM dimensions, as they were

Table 1: Inter-reliability Researcher (R) and Independent Coders (IC)

\begin{tabular}{|c|c|c|c|c|}
\hline & $\mathrm{R}-1^{\text {st }} \mathrm{IC}$ & $R-2^{\text {nd }} I C$ & $1^{\text {st }}$ IC $-2^{\text {nd }}$ IC & Mean \\
\hline 1. The themes represent HT investigative actions & 1 & 0.905 & 0.905 & 0.937 \\
\hline 2. First-order categories grouped appropriately into themes & 0.908 & 0.898 & 0.878 & 0.919 \\
\hline 3a. Names of the themes reflect their description & 0.905 & 0.764 & 0.856 & 0.842 \\
\hline 3b. Names of the themes reflect the categories grouped into the themes & 0.905 & 0.811 & 0.713 & 0.809 \\
\hline Mean & & & & 0.877 \\
\hline
\end{tabular}


repeatedly mentioned by the participants. Hence, 51 first-order categories were identified from the statements previously categorized within the five main dimensions of the VSM, some of them being present in more than one VSM dimension (e.g. risk assessment). First-order categories were then grouped in 22 themes reflecting the core actions taken within a criminal investigation of HT crimes (see Appendix 2).

\section{Human trafficking criminal investigations - core investigative actions}

First, we found that the starting point of an investigation may differ from case to case. While in many cases the investigation starts with the report of a potential case of HT or a suspicion that there may be someone being exploited, as some of the participants pointed out, it is not always clear whether they are themselves dealing with a victim of trafficking. Participant 03 (middle rank police officer) stated:

You quite often get people that would present themselves and ask for help but [...], they do not necessarily know what happens to them, they can't say I am a victim of trafficking, because they don't understand what that is, what they know is that something is happening that is wrong, and it is up to us to try to figure that out, and when you got the language barrier and you try to get the communication, and words don't transcribe the way you want to, it gets complicated

\section{While participant 06 (senior police officer) also said}

If you go back to the very beginning of the story, when a guy walked into the police station, and he said, that he was in a dispute with a guy called [...], and then he starts to talk that there's been other people here coming from Slovakia, and he went home, then came back, ... his story wasn't, it wasn't a brilliant story, it felt like there was a lot more in there than what he told us

Participants also advised that because of the lack of awareness that may exist in regard to the offence and its magnitude, intelligence checks and first investigative diligences (i.e. assessment of the initial information) are conducted to establish the nature and the seriousness of the crime. In this regard Participant 19 (senior police officer) said:

So what we did was to start with basics intelligence checks. I said to him, so the names that you've got and the addresses that you've got, how many addresses that you've got links to these names, how many names do you have linking to other addresses, on the police system, housing system, the Department for Workand Pensions ${ }^{2}$, the Her Majesties' Revenue and Customs ${ }^{3}$, and that was pretty much the beginning, ok, let's see what we've got in terms of intelligence [...]. So I just wanted to have an understanding of what we thought we had and the number

This first intelligence checks and intelligence gathering serves not only to have a better understanding of the offence and its magnitude, but also to identify which is the most suitable investigative team or unit to carry out the investigation (i.e. tasking allocation/resources allocation). As Participant 01 (senior police officer) declared:

For each case and the intelligence gathered from the case, a risk assessment is

\footnotetext{
${ }^{2}$ Department for Workand Pensions: the UK government department responsible for social security benefits.

${ }^{3}$ Her Majesties' Revenue and Customs: the UK government department responsible for tax revenues.
} 
made in order to allocate the case to a specific unit

According to one of the biggest concerns, the uncertainty concerning how long an investigation will last or how complicated the case will become, make resources allocation a challenging task. Hence, resources in terms of time, staff, and money that will be required to conduct the investigation need to be considered. Participant 16 (very senior police officer) stated:

As a detective chief inspector, the balance of different jobs that are ongoing at the same time, and it is quite difficult, we have about hundred crimes per day, $[. .$.$] actually in terms of team of$ detectives that are available to do some work, it is very small, and they got their own work as well

Furthermore, we also found from participants that when establishing the investigation team, most of the sample $(n=15)$ argue that time is spent defining and considering who and which agencies should be part of it. That is, for investigations of HT, other professionals, either from outside the police force or from a different police force than the one who is leading in the investigation, may be asked to join and collaborate through the investigative process. Organization and agencies may be holding vital pieces of information that, unless shared and put together would remain meaningless. Multi-agency collaboration promotes both, intelligence sharing between police forces and intelligence sharing between police and organizations and agencies external to the police force. Thus, collaborating with other agencies and police forces (i.e. Multi-agency collaboration) is seen as a real opportunity for intelligence purposes. Participant 05 (middle rank police officer) declared:

one of the things we were shocked at was, for every agency, not only the police, the amount of opportunities (i.e. to share data) that we had and that have been there for years

While Participant 07 (very senior police officer) also said:

we've got the PND (Police National Database), it is very good, but it only gets in there, the intelligence that is recorded, convictions that are recorded, it hasn't got there the stuff that is not recorded, and so you may need to go and find out more

Nonetheless, despite the consensual views gathered concerning multi-agency collaborations, we also learned that differences between agencies appear to exist with regard with whom they should collaborate. Differences also emerged in the nature and extent of collaborations. For example, while some of the participants view the Modern Slavery Human Trafficking Unit (MSHTU) from the NCA as a potential advisor for specific investigative actions $(n=8)$, others made no reference to this unit at all. Similarly, while some mentioned commercial businesses as possible partners to include when investigating HT $(n=5)$, others did not share that opinion. Despite these discrepancies, the Crown Prosecution Service (CPS) is seen by most of the participants $(n=14)$ as a key partner to include and ask for advice from the very beginning of the investigation, as they can provide guidance on evidence to gather in order to secure the conviction of the offender.

When generating and testing hypotheses, it is highly important to have a discussion with all members of the investigation team in which all of them participate and are able to both, (i) propose ideas and (ii) discuss and plan the proposed course of the investigation. As Participant 04 (middle rank police officer) stated:

We all sit here [referring to the table] and we have a debate on how to do it, you know, we spend time 
This team discussion was viewed by participants as key when (i) determining the purpose and direction of the criminal investigation as well as when (ii) planning the criminal investigation and setting the investigative strategies. Because of (i) the lack of experience investigating HT crimes, compared with other types of crimes, and (ii) the need for an innovative and comprehensive approach when investigating these crimes, team discussion is seen by many, as an opportunity for various agencies to share views, knowledge, and ideas on how to best tackle the case. Thus, despite being often the police who leads the criminal investigation, members from other agencies and organization may also be involved in the discussion concerning investigative issues. As Participant 06 (senior police officer) claimed:

include them [partner agencies] in the part of your investigation strategy and get them involved.

Despite agreement among the participants that team discussion facilitates decisions concerning investigative strategies, such decision-making was still stated by most participants $(n=17)$ as a highly demanding task. Participants narratives also show that risk and situational demands are likely to vary and therefore, many participants $(n=14)$ manifest the need for a constant evaluation of such factors as newly emerging intelligence and the risk and resources available in order to inform investigative decisions. One common example given by the participants was the tension between painstakingly gathering intelligence and evidence/ information to support the criminal investigation (and secure a conviction of the perpetrators) on the one hand, while on the other safe-guarding victims of trafficking, while such evidence gathering was being undertaken. As participant 18 (middle ranking police officer) stated:

here it is the dilemma, you know that a girl of 14 years old is at risk, and you haven't got any evidence but you know that she is at risk, and you have the surveillance team, and you watch her, she gets into the car with the offenders, what do you do? Because if you go and do something, you tell them that you are investigating them and you prove nothing because all you've got is that she got into a car [...] And it is a real dilemma [...] you have to make difficult decisions all the time

Because of these kinds of dilemmas, aggravated by a lack of predictability during the investigation, participants gave huge importance to the need for justifying with strong rationale any of the decisions taken within an investigation. As Participant 20 (a senior police officer) declared:

what do you do if there are concerns that the victims are being exploited or treated worst in between time, you need to put something in place or make a decision not to, and it is very difficult, [...], is about making good and strong decisions, with good rationale, so based on the information I have, there is no sign of extreme violence, no one in a serious risk to harm, and they've been there for quite reasonable amount of time and there is no sign of harm, so you know, they work and they are continuing being exploited but there isn't, the risk is not the highest [.], but if someone gets hurt, they will look at you and say, you knew that was something going on, and you should have done something about it, you choose not to intervene, that is what I say that they are tough decisions to make

Participants also revealed that this uncertainty concerning investigations of HT explains why (i) planning alternative strategies; and (ii) planning post-investigative strategy implementation are 
conducted simultaneously with (iii) the planning of the chosen strategy. Both those first two actions were said to 'secure' the success of an investigation by (i) being prepared in case the situation and the risk changes while conducting the original strategy, as well as (ii) by securing the success of the strategy taken through the implementation a good poststrategy plan (e.g. the provision of reception centres for the victims). Participant 15 (senior officer from a law enforcement agency) stated:

we had something from emergency planning, we want you to go away, find an address that is out of the city, that is safe, that is suitable for ten or more people

Whereas participants wholly agreed as to the effectiveness of multi-agency collaboration (regardless of a lack of uniformity as to what it looks like across the UK), not only when implementing the investigative strategy, but also when securing a good post-investigative strategy, multi-agency work does not come without limitations. Participants disclosed that the objectives and procedures of the various agencies involved in the investigation are likely to differ, thus complicating the investigation. For example, whereas NGOs primarily focus on victim's safeguarding, law enforcement agencies also focus upon evidence gathering and prosecution of offenders. Consequently, participants asserted that for a multi-agency approach to be effective it is important that all involved both understand and agree with the (i) aims and investigative lines of actions; and (ii) the overall objectives, roles and limitations of each member of the team. As Participant 13 (senior officer from a law enforcement agency) reported:

you might have charities there, local authorities there, people from housing benefits, anybody that could potentially help that victim [...], but there's got to be some control over it [...], because people don't want to see victims giving evidence to them (to the social workers) as it could cause some problems in courts so, we need to brief what their role is and what is expected of them

Several participants $(n=14)$ reported that the need for the division of roles and duties is not only exclusive for professionals from outside the police, but that it is also important for the police themselves. That is, roles and responsibilities need to be also allocated to specific members of the investigation team. For example, a member of the investigation team would be exclusively responsible of dealing with victims. While this task is seen as a demanding, and time-consuming practice, we found there was agreement among participants as to the usefulness of this practice (largely due to the reported importance of 'keeping victims on board' during the criminal investigation). As Participant 01 (senior police officer) stated:

from the very beginning of the investigation there is a dedicated officer of the team who is not involved in the investigation per se, but his only responsibility is to care about the victim [...]. It is very expensive but crucial to get victim's cooperation

While victims are viewed as one of the major sources of information to assist an investigation, most participants are aware of the limitations of relying exclusively on the statements of the victims when evidence gathering due to, for example, the possibility of victims going 'missing', or victims possibly lacking credibility in court. Thus, it was found that a need remained to gather other evidence in addition to victims' statements in order to secure convictions of the offenders.

Since HT investigations are both lengthy and complex, participants advised that there is an ongoing need during investigations to evaluate the effectiveness both of the actions taken and of the intelligence gathered (and shared). Such 
continuous monitoring and evaluation is designed to ensure that (i) the objectives are being met; and (ii) any required revision of strategy is promptly undertaken. In light of this finding, we were also advised by participants that debriefing and communication among members of the team becomes, therefore, an opportunity to conduct such ongoing evaluations.

Similar to our findings concerning the lack of agreement among participants as to the appropriate action to take when a HT investigation commences, we also found a lack of consistency concerning views as to when (and how) to conclude an investigation. However, despite this lack of uniformity, what was regularly mentioned by the participants is the need to conduct a final evaluation of the investigation. This is seen as a learning exercise to improve investigations in the future. As participant 14 (director of a law enforcement agency) declared:

making sure that we've identified best practices in relation to learning opportunities for the future so we could understand how to deal with it in the future

After considering the participants' narratives, themes representing 22 core investigative actions were identified. Table 2 shows which actions have been mentioned, at least once, by each of the 21 participants. As Table 2 shows, despite not all actions being cited by all participants, at the very least they were cited by $61.9 \%(n=13)$ of the total sample. However, certain activities (i.e. multiagency collaboration; tactical advice and support; and intelligence gathering and sharing) were cited by all participants.

\section{Theoretical model}

A further examination of the narrative of the interviewees suggested an apparent logical course of investigative actions. Most of these actions usually appeared in sequence, incrementally being linked to the next step to be taken. For example, after the establishment of the investigative team, the

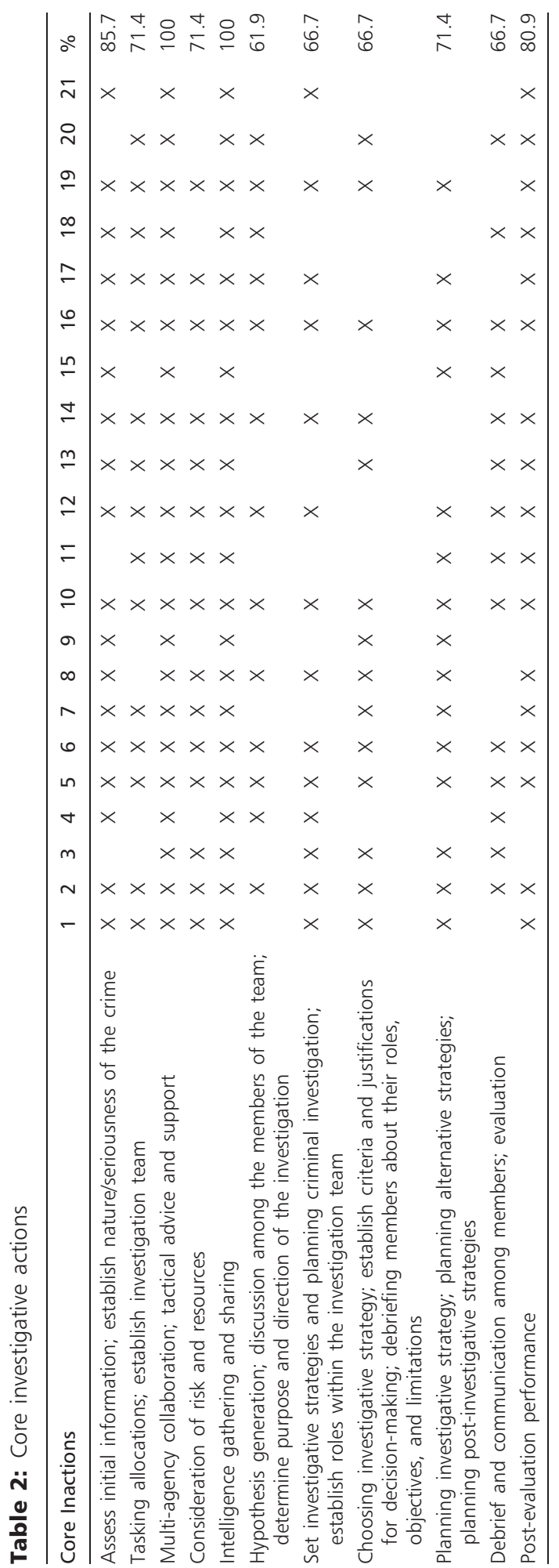


actions commonly stated as the subsequent one was hypothesis(es) generation and identification of routes available to test the hypothesis, along with a discussion among members of the team about potential investigation schemas. Similarly, choosing the investigative strategy, was followed by planning of the strategy. The proposed theoretical framework (Fig. 2) reflects the route in which investigative actions are taken and how they interconnect. As observed in Fig. 2, whereas most of the actions follow a linear path, the core actions of Multi-agency collaboration; Intelligence gathering and sharing; Tactical advice and support; Consideration of risk and resources; and Evaluation and monitoring, would be present through the whole investigative process. The interconnection of these actions, reveals that they are all aspects that need to be considered throughout the investigative process. Furthermore, the need for constant evaluation implies the necessity to 'retake' previous investigative stages whenever it is necessary, in order to accommodate any new investigative need and/or situational demand.

\section{Discussion}

Creating an evidence base that underpins HT criminal investigations was the main aim of the present study. To date, the analysis of legal and policy frameworks has dominated the research agenda, whereas little research has been conducted concerning what occurs in criminal investigations of HT cases (Friesendorf, 2009; Russell, 2017). As such, despite different guides and protocols having been developed, they have not been subjected first to any rigorous scientific scrutiny (Gozdziak and Collett, 2005; Zhang, 2012). Thus, responses to HT have been more centred upon assertions of good practice, rather than being based on any empirical evidence concerning what may actually work in practice (Malloch et al., 2012) . The present study conceptualizes HT investigations under a common framework that is based on the main dimensions of the VSM, which, in turn, underpins a model for the investigation of HT crimes. While research findings show that HT investigations can also fit within the VSM, a deeper examination of the data disclosed that certain actions are commonly taken in an investigation of HT within each of the broad VSM dimensions. Hence, the framework presents a more detailed route of actions (compared with previous investigative frameworks (e.g. Gottschalk, 2006; Smith \& Flanagan, 2000)), that goes from the very start of the investigation till its closure. This will enable both the development of further empirical research on HT investigations and also the provision to professionals of an investigative route of action to follow. Such an outcome would serve as a guidance to practitioners when conducting HT investigations.

Despite various official reports pointing out the lack of coordination and common approach of different police forces when investigating HT crimes (e.g. Hyland, 2016), results from the present study reveal that there would be certain investigative actions present when investigating HT. We found (from the narratives of those professionals, experienced with HT investigations), 22 investigative actions commonly undertaken during such investigations, following a seemingly sequential route. Hence, regardless of the matter that investigations of HT can differ from force to force (in terms of investigative units, capacities and their capabilities, etc.) they can all be embedded within a common model. The Modern Slavery strategy (2014), published in 2014, provides wide guidance when tackling HT from a 4Ps approach (i.e. Pursue, Prevent, Protect, and Prepare), nonetheless, it fails to give professionals with a clear pathway as to which actions to take when investigating HT crimes. The framework proposed within this present study aims to complement the Modern Slavery strategy (2014), by providing professionals with a more detailed (and evidence based) route of actions to follow when investigating a potential case of HT. Likewise, while pressure from the government has been applied recently to prompt police forces to increase and improve HT investigations, it has 


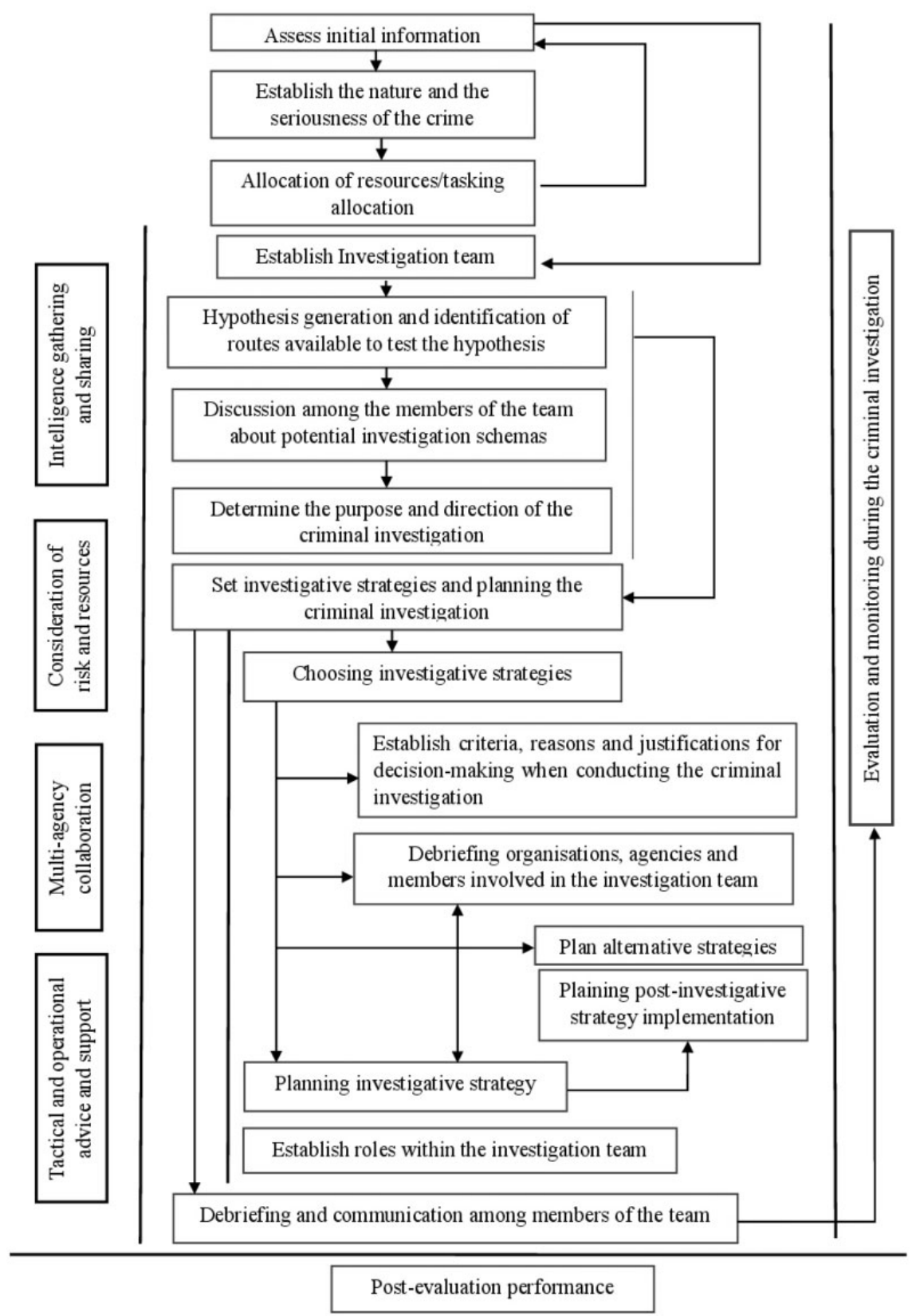

Figure 2: Theoretical framework.

been only recently that police officers have begun to be provided with the knowledge and the training from a team of seconded police officers (i.e. the Modern Slavery Police Transformation Unit) as to how to conduct such investigations. However, the evidence base for such initiatives remains sparse. This situation has apparently resulted in a return to the use of traditional approaches when investigating HT (Farrell and Pfreffer, 2014). While the way in which HT investigations are 
conducted has somewhat changed during the last couple of years or so (through, say, the publication of key reports that have both identified and raised awareness of 'best practices' in the investigation of $\mathrm{HT}$ ), it is argued there is still much to be done before we have a robust evidence of effective criminal investigation of HT. For example, multi-agency and intelligence-led approaches have been both qualified by official reports as 'best' practices to effectively investigate HT crimes (e.g. GRETA, 2016; Hyland, 2016). Consequently, and in line with our findings, most of the police forces are adopting such investigative practices. Nonetheless, the latest reports on HT police investigations point out both these two aspects that still require further improvement (e.g. HMICFRS, 2017). This leaves an opportunity for academic research (and collaboration with practitioners) to further examine HT investigative practices in order to provide a valid and reliable knowledge on how to best conduct such HT investigations. Hence, the theoretical framework in the present study may be used as a tool when examining the investigation of this crime.

The breakdown of the investigative process into core actions enables the examination of each of the separate tasks, as well as connections between one task and another. Such an approach we reckon will enable more exhaustive evaluation both of the entire process, as well as its different stages and tasks. Furthermore, the use of a common framework (when empirically examining and evaluating investigative performance) facilitates the comparison and extrapolation of results. To date, the findings from the research concerning HT investigations has come from case studies (Russell, 2017). While useful to improve the understanding of HT crimes, such studies have had little impact on investigative practices (largely because, it is argued, of the difficulties involved in applying the results of one particular case to other investigations). Therefore, the use of a model (as the one found in the recent study) could help overcome this challenge.

Furthermore, the provision to investigators with a framework that conceptualizes the steps to be taken when investigating HT, which goes beyond the description of the main five stages of any criminal investigation (i.e. problem definition, investigative approaches, solution choice, solution execution, and evaluation), would help professionals to understand and to follow a sequential and logical route of actions. This will not only serve as a guidance for novice HT investigators, but also enable a better understanding for police personnel as to how HT investigations are conducted (and how their individual role fits within it).

An understanding as to how to operate in a multi-agency environment, when to allocate roles and responsibilities or when to discuss potential investigative strategies, may well reduce the use of extra resources by securing that all steps that precede an investigative action has been considered and taken. Furthermore, having a clear pathway may also help professionals when evaluating a criminal investigation by examining which actions have (or have not) been undertaken, and how well these tasks have been conducted. Likewise, the inclusion in the model of specific actions, such as planning post-investigative strategies), reduces the chances that such actions are neglected to be considered when planning, allocating of resources, and investigating. Moreover, the utilization of such a common model by both, professionals and academics, could well promote the cohesion between academia and practitioners by enabling the implementation of research findings into investigative practices. Thus, the theoretical framework presented may well serve as a bridge for the inclusion of empirical-based knowledge in investigative practices. As such, this framework provides a more pragmatic and evidence-based model that considers both professional experience and empirical findings.

\section{Limitations}

The findings presented here are not without their limitations. Most importantly, the present investigation examines HT investigation within 
England and Wales. That is, data has been gathered from police forces, agencies, and organizations that investigate HT crimes in England and Wales and therefore, HT investigations conducted in other countries with different legislative frameworks, criminal justice systems, and police structures may vary. Furthermore, limitations inherent to qualitative analyses such as small sample size or participants' social desirability bias, should also be considered when interpreting the results. However, assurances were given as to the anonymity of the participants allowing them to talk freely (which they appeared to do). Further, while the size and nature of selection of the participant sample may mean that the findings are not generalizable, the extensive experience of the participants has shone a light in an area bereft of prior meaningful research. Participants were selected not only because of their role within the investigation but because of their combined unparallelled expertise in the field. The most senior professionals of current leading agencies and organizations on the realm of HT were included (e.g. GLAA, Modern Slavery Police Transformation Unit, Independent Anti-Slavery Crime commissioner office, NCA, etc.). Likewise, the sample also included professionals from those police forces that had been named in different official reports as exemplars of HT crimes investigations. As such, despite the reduced sample size, our study included peerless expert knowledge in the field of HT investigations in the UK. In any event, the study presents an emergence of a theoretical framework, representing a model for the investigation of HT crimes in the UK (a country which has shown a global lead on HT investigations). It may well be the case that such findings also have the potential to be transferable (or at least most of the actions therein) to other countries and their criminal justice systems. It is suggested that further research should be conducted in the UK (and elsewhere) to establish whether the proposed model has applicability to the field. Another aspect to consider is that, the theoretical framework covers exclusively the police investigation of HT crimes. Because of the complexity of HT crimes, criminal investigation must be complemented with prevention and protection approaches (e.g. education, awareness raising, victims' support). As such, the proposed framework, while believed to be useful from an investigation perspective, is not intended as an exhaustive set of activities that is required to be taken when tackling HT.

\section{Conclusions}

Overall, the present study proposes a framework that is geared to reduce of one of the major gaps in our understanding on HT crimes; that of its criminal investigation. The present study encourages the academic community to empirically research HT investigations through the use of methodologies that enable the extrapolation and comparison of results. Thus, the theoretical framework does not only aim to conceptualize HT investigations but also, to serve as a tool for further examination and evaluation of HT investigations under a common framework. Such a framework is expected to serve as a much-required bridge to help promote the necessary integration of empirical knowledge into investigative practices.

\section{References}

Berg, M. E., Dean, G., Gottschalk, P., and Karisen, J. T. (2008). 'Police Management Roles as Determinants of Knowledge Sharing Attitude in Criminal Investigation'. International Journal of Public Sector Management 21(3): 271-284.

Braun, V. and Clarke, V. (2006). 'Using Thematic Analysis in Psychology'. Qualitative Research in Psychology 3(2): 77-101.

Bruns, M. (2015). 'A Network Approach to Organize Crime by the Dutch Police Sector'. Police Practice and Research 16(2): 161-174.

Chen, H., Schroeder, J., Hauck, R. V. et al. (2003). 'COPLINK Connect: Information and Knowledge Management for Law Enforcement'. Decision Support Systems 34(3): 271-285.

Dean, G., Filstad, C., and Gottschalk, P. (2006). 'Knowledge Sharing in Criminal Investigations: An Empirical Study of 
Norwegian Police as Value Shop'. Criminal Justice Studies 19(4): 423-437.

Department of State (2013). Trafficking in persons report. https://www.state.gov/j/tip/rls/tiprpt/2013/ (accessed 21 January 2018).

Farrell, A., McDevitt, J., and Fahy, S. (2010). 'Where Are All the Victims: Understanding the Determinants of Official Identification of Human Trafficking Incidents'. Criminology and Public Policy 9(2): 201-234.

Farrell, A. and Pfeffer, R. (2014). 'Policing Human Trafficking: Cultural Blinders and Organisational Barriers'. The Annals of the American Academy of Political and Social Science 653(1): 46-64.

Friesendorf, C. (2009). Strategies against Human Trafficking: The Role of the Security Sector. Vienna: National Defence Academy and Austrian Ministry of Defence and Sport

Gallagher, A. and Holmes, P. (2008). 'Developing an Effective Criminal Justice Response to Human Trafficking: Lessons from the Front Line'. International Criminal Justice Review 18(3): 318-343.

Glomseth, R., Gottschalk, P., and Karlsen, J. T. (2007). 'Leadership Roles as Determinants of Criminal Investigation Performance: An Empirical Study of Norwegian Police as Value Shop'. International Journal of Management and Enterprise Development 4(2): 128142.

Gottschalk, P. (2006). Knowledge Management Systems in Law Enforcement: Technologies and Techniques. Hersey, USA: Idea Group Publishing.

Gottschalk, P. (2007). 'Predictors of Police Performance: An Empirical Study of Norwegian Police as Value Shop'. International Journal of Information Management 27(1): 36-48.

Gottschalk, P., and Holgersson, S. (2006). 'Stages of Knowledge Management Technology in the Value Shop: The Case of Police Investigation Performance'. Expert Systems 23(4): 183-193.

Gozdziak, E. M., and Collett, E. A. (2005). 'Research on human trafficking in North America: A review of the literature'. International Migration 43: 99-128.

GRETA (2016). $6^{\text {th }}$ General report on GRETA's activities. Group of Experts on Actions against Trafficking in Human Beings. https://rm.coe.int/1680706a42 (accessed 21 January 2018).

HMICFRS (2017). Stolen freedom: The policing response to modern slavery and human trafficking. https://www.justiceinspectorates.gov.uk/hmicfrs/wp-content/uploads/ stolen-freedom-the-policing-response-to-modern-slavery-and-human-trafficking.pdf (accessed 21 January 2018).

Hyland, K. (2016). Independent Anti-Slavery Commissioner. Annual report 2015-2016.
Kingshott, B. F. (2015). Investigation of Human Trafficking. In Palmiotto, M. J. (ed.), Combating Human Trafficking. A Multidisciplinary Approach. Boca Raton: CRC Press, pp. 91-119.

Konrad, R. A., Trapp, A. C., Palmbach, T. M., and Blom, J. S. (2017). 'Overcoming Human Trafficking via Operation Research and Analytics: Opportunity for Methods, Models and Applications'. European Journal of Operational Research 259(2): 733-745.

Lone, J. A., Garnas, A., Myklebust, T. et al. (2017). 'Organisational Climate and Investigation Performance in the Norwegian Police: A Qualitative Study'. Journal of Investigative Psychology and Offender Profiling 14(3): 227-245.

Luen, T. W. and Al-Hawamdeh, S. (2001). 'Knowledge Management in the Public Sector: Principles and Practices in Police Work'. Journal of Information Science 27(5): 311-318.

Malloch, M., Warden, T., and Hamilton-Smith, N. (2012). Care and support for adult victims of trafficking in human beings: a review. Scottish Centre for Crime and Justice Research. http://www.gov.scot/socialresearch.

Modern Slavery Strategy (2014). UK: Home Office.

NRM (2016). National Referral Mechanism statistics- end of year summary 2016. http://www.nationalcrimeagency. gov.uk/publications/national-referral-mechanism-statistics/2016-nrm-statistics/788-national-referral-mechanism-statistics-end-of-year-summary-2016/file (accessed 21 January 2018).

Russell, A. (2017). 'Human Trafficking: A Research Synthesis on Human Trafficking Literature in Academic Journals from 2000-2014'. Journal of Human Trafficking 4(2): 114-123.

Sigmon, J. N. (2008). 'Combating Modern Day Slavery: Issues in Identifying and Assisting Victims of Trafficking Worldwide'. Victims and Offenders 3(2-3): 245-257.

Smith, N., and Flanagan, C. (2000). The Effective Detective: Identifying the Skills: Identifying the Skills of an Effective SIO. Police Research Series Paper 122. London, UK: Policing and Reducing Crime Unit.

Stelfox, P. (2009). Criminal Investigation: An Introduction to Principles and Practice. NY, USA: William Publishing.

The Global Index (2017). https://www.globalslaveryindex. org (accessed 21 January 2018).

UNODC (2014). Global Report on Trafficking in Persons. United Nations Office and Drugs Crime. Vienna: United Nations publication.

Van der Watt, M. (2014). 'Towards a Complex-System Understanding for Combating Human Trafficking'. Culture, Police and Law Enforcement 3: 218-299.

van der Watt, M., and van der Westhuizen, A. (2017). '(Re)Configuring the Criminal Justice Response to 
Human Trafficking: A Complex System Perspective'. Police, Practice and Research 18(3): 218-229.

Verhoeven, M. and Van Gestel, B. (2011). 'Human Trafficking and Criminal Investigation Strategies in the
Amsterdam Red Light District'. Trends in Organised Crimes 14(2-3): 148-164.

Zhang, S. (2012). 'Measuring labour trafficking: a research note'. Crime, Law and Social Change 58: 469-482.

Appendix 1: Dimensions, definitions, and representative statements

\begin{tabular}{|c|c|c|}
\hline Dimension & Definition & Representative Statement \\
\hline Problem definition & $\begin{array}{l}\text { This phase involves working with parties in order to determine the } \\
\text { extent and nature of the crime and how it will be defined. } \\
\text { Furthermore, this phase also involves deciding on the overall inves- } \\
\text { tigative approach for the case, not only in terms of information } \\
\text { acquisition but also of forming an appropriate investigative team } \\
\text { to handle the case. }\end{array}$ & $\begin{array}{l}\text { 'I just wanted to have an under- } \\
\text { standing of what we thought we } \\
\text { had and the number' (Participant } \\
\text { 06) }\end{array}$ \\
\hline $\begin{array}{l}\text { Investigative } \\
\text { approaches }\end{array}$ & $\begin{array}{l}\text { This involves the actual generation of hypotheses and hence the } \\
\text { generation of ideas and actions plans for conducting the investi- } \\
\text { gation. As such, it sets the direction and tone of the investigation } \\
\text { and is very much influenced by the composition of the member } \\
\text { of the investigative team. For example, the experience level of in- } \\
\text { vestigators and their preferred investigative thinking style might be } \\
\text { a critical success factor in this second primary activity of the value } \\
\text { shop }\end{array}$ & $\begin{array}{l}\text { 'We all sit here and we have a } \\
\text { debate on how to do it, you } \\
\text { know, we spend time' (Participant } \\
\text { 04) }\end{array}$ \\
\hline Solution choice & $\begin{array}{l}\text { This represents the decision of choosing between alternatives. While } \\
\text { the least important primary activity in the value shop in terms of } \\
\text { effort and time, it might be the most important in terms of value. } \\
\text { In this case, trying to ensure as far as it is possible that what is } \\
\text { decided on to do is the best option to follow to get an effective } \\
\text { investigative result. A successful solution choice is dependent on } \\
\text { two requirements. First, alternative investigation steps were identi- } \\
\text { fied in the problem solving approaches activity. It is important to } \\
\text { think in terms of alternatives. Otherwise, no choice can be made. } \\
\text { Next, criteria for decision-making have to be known and applied } \\
\text { to the specific investigation. }\end{array}$ & $\begin{array}{l}\text { 'we might think, you know what, } \\
\text { we don't know what they are } \\
\text { doing in this area and we need } \\
\text { to get some evidence about that } \\
\text { and we could do it, let's see at } \\
\text { these contacts, let's get a request } \\
\text { from their home country, and } \\
\text { find what intelligence is out } \\
\text { there' (Participant 10) }\end{array}$ \\
\hline $\begin{array}{l}\text { Investigation } \\
\text { implementation }\end{array}$ & $\begin{array}{l}\text { This represents communication, organizing, investigating, and imple- } \\
\text { menting decisions. It involves storing out from the mass of infor- } \\
\text { mation coming into the incident room about a case and directing } \\
\text { the lines of enquiry as well as establishing the criteria used to } \\
\text { eliminate a possible suspect for future scrutiny in the } \\
\text { investigation. }\end{array}$ & $\begin{array}{l}\text { 'We started to do a little bit of sur- } \\
\text { veillance, the hardest thing is ob- } \\
\text { viously to get the resources and } \\
\text { the staff,' (Participant 18) }\end{array}$ \\
\hline Evaluation & $\begin{array}{l}\text { This involved monitoring activities and the measurement on how } \\
\text { well the solution solved the original problem or met the original } \\
\text { need. This is where the command and control chain of authority } \\
\text { comes into play for police organizations and where the determin- } \\
\text { ation of the quality and quantity of the evidence is made as the } \\
\text { whether or not to charge and prosecute and identified offender in } \\
\text { a court of law. }\end{array}$ & $\begin{array}{l}\text { 'Making sure that we've identified } \\
\text { best practices in relation to learn- } \\
\text { ing opportunities for the future } \\
\text { so we could understand how to } \\
\text { deal with it in the future' } \\
\text { (Participant 14) }\end{array}$ \\
\hline
\end{tabular}


Appendix 2: Dimension — First-order categories — themes

DIMENSIONS

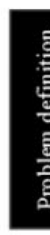

Access to initial case information

Existent intelligence already known (c.g. databases)

FIRS-ORDER CATEGORIES

THEMES

Access to initial case information
Existent intelligence already known (e.g. databases)

Definition of the members of the investigation team

Consideration of other agencies and organisations (due to its resources,

capabilities/ capacities and competencies) that may support the

investigation

Appointing a lead of the criminal investigation

Understanding of the offence and the case

Identify the best way to tackle the offence

Consideration of polices and guidance

Discussion of the strategy

Establish aims and objectives

Points to prove

Consider the evidence required to prove the offence

Establish priorities

Define and plan investigation

Resources (Money, time, staff available, while balancing other duties)

Risk assessment

Support from other agencies and organisations

Tactical and operational advice

Selecting investigative strategy

Discussion with members of the team (strategies, evidence, etc.)

Establish emergency plan

Planning what to do after deciding upon an investigative strategy

Paralleling evidence

$\longrightarrow$

Intelligence gathering and haring among different forces, agencies and organisation

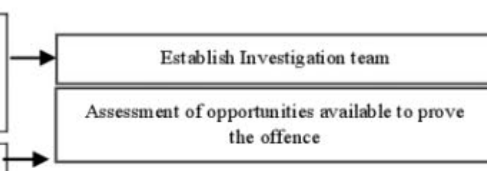

Define objectives and priorities when collecting data

Decision making underlined by strong reasons and justifications

Consider risk and safeguarding matters

Considering resources

Debriefing organisations and agencies about their role and objectives of

the investigation

Make sure members of the team understand the strategy and objectives

Partnership and networking with other organisations and agencies

Work closely with other police forces and law enforcement agencies

Use of capacities/capabilities, intelligence, resources and competencies

from other forces and agencies

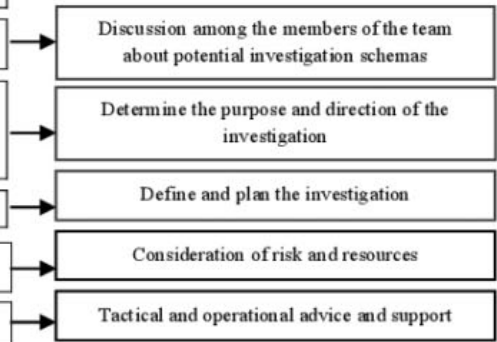

Allocate officers with specific roles

Give agencies and organisations roles with in the investigative team

according to their capabilities, resources and competencies

\begin{tabular}{|c|} 
Plaining post-investigative strategy \\
implementation
\end{tabular}

Intelligence on how best conduct the strategy

Planning and timing the investigative strategy

Planning how to gather evidence and how to present it in court

Look at evidential opportunities

Establish criteria, reasons and justifications for decision-making when conducting the criminal

$$
\text { investigation }
$$

Debriefing organisations, agencies and members involved in the investigation team about their

roles, objectives, and limitations within the investigation

$\rightarrow \longrightarrow$ investigation

Discussion and communication among member team

Establish channels of communication

Consider evidence gathered

Establish roles within the investigation team

Evaluation of the weaker points of the investigation

Identification of good practices

Evaluation risk

Evaluation of information and results to plan future steps

Planning investigative strategy

Debriefing and communication among members of the team 
Appendix 3: Core actions - First-order categories - Description

\begin{tabular}{|c|c|}
\hline Themes-Core Actions & First-Order Categories \\
\hline Assess initial information & $\begin{array}{l}\text { Access to initial case information } \\
\text { Existent intelligence already known } \\
\text { (e.g. databases) }\end{array}$ \\
\hline $\begin{array}{l}\text { Establish the nature and the } \\
\text { seriousness of the crime }\end{array}$ & $\begin{array}{l}\text { Extent of the crime } \\
\text { Nature of the crime } \\
\text { Seriousness of the crime and risk } \\
\text { assessment }\end{array}$ \\
\hline $\begin{array}{l}\text { Allocation of resources / } \\
\text { Tasking allocation }\end{array}$ & $\begin{array}{l}\text { Investigative team allocation } \\
\text { Police force allocation }\end{array}$ \\
\hline $\begin{array}{l}\text { Consideration of risk and } \\
\text { resources (staff, money, } \\
\text { time, other duties) }\end{array}$ & $\begin{array}{l}\text { Resources (Money, time, staff, while } \\
\text { balancing other duties) } \\
\text { Risk assessment }\end{array}$ \\
\hline $\begin{array}{l}\text { Tactical and operational } \\
\text { advice and support }\end{array}$ & $\begin{array}{l}\text { Support from other agencies and } \\
\text { organizations } \\
\text { Tactical and operational advice }\end{array}$ \\
\hline Multi-agency collaboration & $\begin{array}{l}\text { Partnership and networking with } \\
\text { other organizations } \\
\text { Work closely with other police } \\
\text { forces and law enforcement } \\
\text { agencies } \\
\text { Use of capacities/capabilities, intelli- } \\
\text { gence, resources, and competen- } \\
\text { cies from other forces and } \\
\text { agencies }\end{array}$ \\
\hline $\begin{array}{l}\text { Intelligence gathering and } \\
\text { sharing among different } \\
\text { forces, agencies and } \\
\text { organizations, and } \\
\text { businesses. }\end{array}$ & $\begin{array}{l}\text { Intelligence gathering and sharing } \\
\text { among different forces, agencies } \\
\text { and organizations, and business. } \\
\text { Capturing intelligence } \\
\text { Ensuring the intelligence flow }\end{array}$ \\
\hline
\end{tabular}

Establish Investigation team

Hypothesis generation and identification of routes available to test the hypothesis

Discussion among the members of the team about potential investigation schemas

Determine the purpose and direction of the investigation

Definition of the members of the investigation team

Consideration of other agencies and organizations (due to its resources, capabilities/ capacities, and competencies) that may support the investigation.

Appointing a lead of the criminal investigation

Understanding of the offence and the case

Identify the ways to tackle the offence

Consideration of polices and guidance

Discussion of the investigative approach and investigative strategies

Establish aims and objectives

Points to prove

Consider the evidence required to

\section{Description}

Conduct first intelligence checks, either from the initial case report or the information that is available in the police system.

Determine whether the case is a potential case of MS or HT or not, as well as determine its seriousness and its extension (i.e. local, regional, national, international).

Allocate the case to a police force and to an investigative team within the police force.

Consideration of the risks attached when investigating modern slavery crimes as well as the resources available (i.e. money, staff, time).

Ask for and receive both, advice and support, from other forces, agencies and organizations (either governmental or non-governmental).

Establish a multiagency collaboration considering police forces, law enforcement agencies, and other agencies and organizations (either governmental or non-governmental). By adopting a multiagency approach, it is pretended to facilitate the access to intelligence, capabilities and resources form other forces, agencies and organizations.

Gathering and sharing intelligence of the case from: (i) files and databases (either from the local and national police database or from agencies and organizations external to the police force); (ii) passive intelligence (e.g. CCTV); and (iii) persons (either witnesses or members within the police force or other organizations that may have intelligence of the case). prove the offence

Establish priorities

Define and plan the investigation
Establish an investigation team to carry out the investigation (i) by appointing a leader to coordinate and run the investigation; and (ii) by considering not only officer within the police force, but also members from other agencies and organizations that, because of its resources, capabilities and competencies, may be able to support the criminal investigation.

By having a broad understanding of the offence and the specific case, identify potential routes to prove the offence.

Brain storming and team discussion about the investigative approaches and investigative strategies to take in the criminal investigation.

Determine the purpose and direction of the investigation considering (i) intelligence; (ii) evidential opportunities identified; and (iii) aims and objectives of the criminal investigation. 


\section{Appendix 3: Continued}

\begin{tabular}{|c|c|c|}
\hline Themes-Core Actions & First-Order Categories & Description \\
\hline $\begin{array}{l}\text { Set investigative strategies } \\
\text { and planning the criminal } \\
\text { investigation }\end{array}$ & Choosing investigative strategies & $\begin{array}{l}\text { Define and plan the route and steps of the criminal } \\
\text { investigation in accordance to the approach and } \\
\text { purpose of the investigation. }\end{array}$ \\
\hline $\begin{array}{l}\text { Establish roles within the in- } \\
\text { vestigation team }\end{array}$ & $\begin{array}{l}\text { Allocate officers to specific roles } \\
\text { Give agencies and organizations } \\
\text { roles within the investigative team } \\
\text { according to their capabilities, } \\
\text { resources, and competencies }\end{array}$ & $\begin{array}{l}\text { Allocate roles and duties to the members of the inves- } \\
\text { tigation team. }\end{array}$ \\
\hline $\begin{array}{l}\text { Choosing investigative } \\
\text { strategies }\end{array}$ & $\begin{array}{l}\text { Selecting investigative strategy } \\
\text { Discussion with members of the } \\
\text { team (strategies, evidence, etc.) }\end{array}$ & $\begin{array}{l}\text { Selection of the most suitable investigative strategy to } \\
\text { conduct considering opinions, ideas, and knowledge } \\
\text { of the different members from the investigative } \\
\text { team. }\end{array}$ \\
\hline $\begin{array}{l}\text { Establish criteria, reasons, } \\
\text { and justifications for deci- } \\
\text { sion-making when con- } \\
\text { ducting the criminal } \\
\text { investigation }\end{array}$ & $\begin{array}{l}\text { Define objectives and priorities } \\
\text { when collecting data } \\
\text { Decision-making underlined by } \\
\text { strong reasons and justifications } \\
\text { Consider risk and safeguarding } \\
\text { matters } \\
\text { Considering resources }\end{array}$ & $\begin{array}{l}\text { Establish criteria to follow when conducting investiga- } \\
\text { tive strategies considering: (i) safe-guarding duties; } \\
\text { (ii) risk involved; (iii) resources available to investi- } \\
\text { gate the case; and (iv) the need to gather evidence } \\
\text { to prove the offence. Decision-making during the } \\
\text { investigative strategy must be supported by strong } \\
\text { rationality. }\end{array}$ \\
\hline $\begin{array}{l}\text { Debriefing organizations, } \\
\text { agencies, and members } \\
\text { involved in the investiga- } \\
\text { tion team about their } \\
\text { roles, objectives, and limi- } \\
\text { tations within the } \\
\text { investigation }\end{array}$ & $\begin{array}{l}\text { Debriefing organizations and agen- } \\
\text { cies about their role and object- } \\
\text { ives within the investigation } \\
\text { Make sure members of the team } \\
\text { understand the strategy and } \\
\text { objectives }\end{array}$ & $\begin{array}{l}\text { All members of the investigative team must be aware } \\
\text { and understand, which is the purpose of the inves- } \\
\text { tigation, as well as which are their roles, duties, } \\
\text { and limitation within the criminal investigation. }\end{array}$ \\
\hline $\begin{array}{l}\text { Planning investigative } \\
\text { strategy }\end{array}$ & $\begin{array}{l}\text { Intelligence on how best conduct } \\
\text { the strategy } \\
\text { Planning and timing the investiga- } \\
\text { tive strategy } \\
\text { Planning how to gather evidence } \\
\text { and how to present it in court } \\
\text { Look at evidential opportunities }\end{array}$ & $\begin{array}{l}\text { Planning the routes and the steps of a criminal inves- } \\
\text { tigation by establishing time lines and clear object- } \\
\text { ives considering the mechanism available to gather } \\
\text { evidence. }\end{array}$ \\
\hline $\begin{array}{l}\text { Planning post-investigative } \\
\text { strategy implementation }\end{array}$ & $\begin{array}{l}\text { Establish emergency plan } \\
\text { Planning what to do after an } \\
\text { investigative strategy }\end{array}$ & $\begin{array}{l}\text { Consideration of possible outcomes after the imple- } \\
\text { mentation of an investigative strategy and plan } \\
\text { future actions in accordance with them. }\end{array}$ \\
\hline $\begin{array}{l}\text { Planning alternative } \\
\text { strategies }\end{array}$ & Paralleling evidence & $\begin{array}{l}\text { Consideration of alternative strategies to gather } \\
\text { evidence. }\end{array}$ \\
\hline $\begin{array}{l}\text { Debriefing and communica- } \\
\text { tion among members of } \\
\text { the team }\end{array}$ & $\begin{array}{l}\text { Discussion and communication } \\
\text { among members of the team } \\
\text { Establish channels of } \\
\text { communication } \\
\text { Consider evidence gathered }\end{array}$ & $\begin{array}{l}\text { Communication among members of the team and } \\
\text { periodical debriefing about the progress of the } \\
\text { investigation. }\end{array}$ \\
\hline $\begin{array}{l}\text { Evaluation and Monitoring } \\
\text { during the criminal } \\
\text { investigation }\end{array}$ & $\begin{array}{l}\text { Evaluation risk } \\
\text { Evaluation of information and } \\
\text { results to plan future steps }\end{array}$ & $\begin{array}{l}\text { Constant evaluation and assessment of any new infor- } \\
\text { mation about the case, and the risk involved when } \\
\text { investigating, in order to redefine the investigative } \\
\text { strategy if necessary. }\end{array}$ \\
\hline Post-evaluation performance & $\begin{array}{l}\text { Evaluation of the weaker points of } \\
\text { the investigation } \\
\text { Identification of good practices }\end{array}$ & $\begin{array}{l}\text { Evaluation of the performance of the criminal investi- } \\
\text { gation considering weak and strong points. }\end{array}$ \\
\hline
\end{tabular}

